This study examined why female adolescents choose to opt out of the math pipeline during high school more often than males, which has implications for their long-term careers.

\title{
Explaining Gendered Math Enrollments for NSW Australian Secondary School Students
}

\author{
Helen M. G. Watt
}

Many researchers have argued that females who discontinue their mathematical education in high school or soon after prematurely restrict their educational and career options (Heller and Parsons, 1981; Meece, Wigfield, and Eccles, 1990; Secada, 1989). Math has been identified as the critical filter that limits access to many high-status, high-income careers (Sells, 1980) through acting as a gateway to many careers and fields of study. Not taking math can restrict or exclude people from certain kinds of university degrees or other forms of education and training, which can lead to many highstatus, high-income careers. The participation of girls and women in mathematics decreases markedly as they progress to higher educational and professional levels (Herzig, 2004), and this flow-on effect has sometimes been termed the math pipeline (Stage and Maple, 1996). Women who discontinue their mathematical studies earlier than men may be less likely to attain highly prestigious and highly paid jobs that depend on prior math. They are consequently less likely to secure those high-status, high-income careers that depend on prior math participation. Since Sells' 1980 article, a burgeoning interest into the reasons that contribute to gendered participation at all stages of the math pipeline has been triggered.

Why do males continue to outnumber females in the field of mathematics after more than two decades of research investigating gendered math participation? It is necessary to identify the multiple points at which females opt out of the math pipeline and understand the reasons for their decisions 
to discontinue math at each of those points. In the long term, this understanding will permit researchers and educators to promote those factors that enhance females' retention in math.

School is a particularly critical context, since it permits the greatest access to be able to ask students about their decisions and perceptions before they self-select out of further studies in general or out of math-related studies in particular. The study examined in this chapter explores the gender difference in math participation in senior high school within the State of New South Wales (NSW) in Australia and major influences on this gendered participation. Identification of important predictors of boys' and girls' math participation will provide valuable guidance regarding how to promote adolescents' choices to continue to participate in the math pipeline, particularly for girls.

\section{Context for the Study}

Most research investigating expectancy-value influences on math participation has been concentrated in the United States, where gendered high school math participation has been documented in terms of the number of high school math courses taken (Eccles (Parsons), 1984a; Eccles, 1985). The organizational structure of math courses in U.S. schools does not lend itself to the study of this phenomenon as directly as does the NSW Australian context. In the United States, courses are structured according to topic areas, and each year students can decide which courses to take. Some topics are generally regarded as less difficult (for example, general math and beginning algebra), while others are regarded as the most difficult (for example, calculus and trigonometry), even though there is no formal classification of the difficulty levels for the various topic areas. Operationalizing math participation in terms of the number of courses that students undertake does not necessarily imply participation in increasingly higher-order and more complex mathematics, because courses in that context are not structured along an explicit underlying continuum of complexity.

In order to undertake an analysis involving the extent to which students choose to participate in more complex math, what is ideally required is a choice structure where students' course selections explicitly reflect their participation along a continuum of increasingly more demanding mathematics. The State of NSW in Australia provides such a context. This is an ideal location for studying gendered choices in terms of course enrollment, since the extent of participation in high-level math can be readily and effectively operationalized during the senior years. In senior grades 11 and 12 , which lead up to a major external examination supplemented by withinschool assessment results called the Higher School Certificate (HSC), students elect which subjects to study. In addition, they select the difficulty level of those subjects. Although it is not compulsory to undertake math in senior high school, the overwhelming majority of students choose to do so. 
At the lowest difficulty level is "Maths in Practice," followed by the basic but more demanding "Maths in Society," with the difficulty increasing in unit value through 2-unit (2U), 3-unit (3U), and the most advanced 4-unit (4U) math (MacCann, 1995). This sequence provides a naturally occurring ordered metric to measure students' participation in increasingly complex math in high school, and NSW therefore provides an ideal context for studying gender differences in math enrollment.

All courses within the HSC curriculum are based on a unit structure in which a unit is worth fifty marks. The lowest Maths in Practice and Maths in Society courses are worth two units each and are independent of each other and also of the other courses. The $2 \mathrm{U}$ course is "related" to the $3 \mathrm{U}$ course in that the $2 \mathrm{U}$ and $3 \mathrm{U}$ candidates share a common paper, and the $3 \mathrm{U}$ candidates sit an additional paper; $3 \mathrm{U}$ and $4 \mathrm{U}$ math are similarly related. The lowest Maths in Practice course, and also the next lowest Maths in Society course, although to a lesser extent, address topics intended to be relevant to "real life," for example, consumer arithmetic. The $2 \mathrm{U}$ course (the material which is studied by all $2 \mathrm{U}, 3 \mathrm{U}$, and $4 \mathrm{U}$ candidates) covers a range of more abstract topics, for example, probability, trigonometry, and algebra. It is the $2 \mathrm{U}$ course that is required for many university degrees that have a math prerequisite. The $3 \mathrm{U}$ course (studied by all $3 \mathrm{U}$ and $4 \mathrm{U}$ candidates) visits these topics in greater depth, and includes more difficult problems, for example, regarding rates of change. The highest $4 \mathrm{U}$ course, studied only by $4 \mathrm{U}$ candidates, includes complex advanced topics such as motion in a circle, volumes by slicing, conics, and complex numbers, which are otherwise studied by students undertaking a math major at university.

\section{Theoretical Framework}

The expectancy-value theory of Eccles and colleagues (for an overview, see Eccles (Parsons) and others, 1983; Eccles, 2005; Wigfield and Eccles, 2000) was developed specifically to explain students' gendered choices and achievement in math. In this theory, educational and vocational choices are most directly related to individuals' expectations for success and the values that they attach to various tasks. Expectancies and values have been found to relate to math course enrollment choices and mathematical achievement (Eccles (Parsons) and others, 1983; Eccles (Parsons), 1984a; Eccles, 1985; Wigfield, 1994). Values have been found to powerfully predict enrollment choices, while expectancies have better predicted performance (Eccles (Parsons) and others, 1983; Eccles, Adler, and Meece, 1984; Updegraff, Eccles, Barber, and O'Brien, 1996).

Intrinsic value has been identified as a major predictor of math participation choices in both high school and college (see Benbow and Minor, 1986; Updegraff, Eccles, Barber, and O'Brien, 1996; Watt, forthcoming). It has been described as similar to the construct of intrinsic motivation defined 
by Deci and colleagues (Deci and Ryan, 1985; Deci, Vallerand, Pelletier, and Ryan, 1991) and by Harter (1981), being concerned with engaging in a task out of interest or enjoyment.

In this study, I also measure self-perceptions related to math, which combines adolescents' "expectations for success" and "perceptions of math talent." Expectations for success are shaped over time by the individual's experiences and his or her interpretations of those experiences (see Eccles and Wigfield, 1995). They are beliefs about how well an individual will perform on an impending task, conceptually distinct from ability perceptions, which are perceptions of one's current competence at a given activity (Eccles (Parsons) and others, 1983). Perceptions of talent effectively tap the notion of ability distinct from performance (see Watt, 2002b, 2004) and have been previously demonstrated to relate to adolescents' intended senior high school math course choices (Watt and Bornholt, 1994).

An increasing emphasis on gendered participation rather than achievement in the expectancy-value literature has coincided with large metaanalyses that have challenged the view of females as achieving less well than males in mathematics. Differing math achievement does not explain the gender differences in math participation, and this is why it is so important to study adolescents' perceptions about math. Two comprehensive metaanalyses (Friedman, 1989; Hyde, Fennema, and Lamon, 1990) established that males and females generally perform equivalently in secondary school math. In studying influences on gendered math participation, Eccles and colleagues have argued that it is still important to include achievement measures as a control (see Updegraff, Eccles, Barber, and O'Brien, 1996), because success expectancies tend to exert less influence on course choices once actual ability is taken into account (see Eccles, 1984b; Eccles, Adler, and Meece, 1984). Including previous math achievement also permits examination of whether both boys and girls choose to participate in math at levels commensurate with their demonstrated abilities. In this study, measures of prior and later mathematical achievement were included in modeling the influences of intrinsic values, and self-perceptions of mathematical talent and expectancies for success, on senior high school math course selections.

\section{Goals of the Study}

Within the context of NSW Australia, the specific goals of the study examined here were to

- Establish the extent to which boys' senior high school math participation exceeded girls' participation.

- Compare boys' and girls' self-perceptions, intrinsic value, and achievement in math.

- Model the influences of gender, prior and current mathematical achievement, self-perceptions, and intrinsic value on boys' and girls' math course choices. 
These goals first establish the extent to which gendered math participation continues to be an issue in the context of NSW Australian senior high school years and then examine whether boys have higher math achievement, self-perceptions, or intrinsic values as potential explanations. Finally, statistical models measure the impact of key expectancy-value predictors on boys' and girls' senior high school math participation. The findings from this study imply important recommendations concerning where educators and parents should focus to promote boys' and especially girls' mathematical participation.

\section{Method}

This section first details characteristics for the study participants, then outlines procedures for data gathering, and provides descriptions of the measures that were used. The methods of analyzing the data are finally overviewed in relation to each key research question.

Sample and Setting. The study participants were 459 adolescents who were in grade 9 when the longitudinal study commenced in 1996 and grade 11 at the final time point in 1998. Sixty-five percent of participants were present for all three occasions (specifically, ninth, tenth, and eleventh grades), and 88 percent were present for at least two. The sample contained 43 percent females, and mainly English-speaking background (ESB) students ( 73 percent), with the largest ethnic subgroup being Asians (22 percent). Participants were from three upper-middle-class (Australian Bureau of Statistics, 1991) coeducational secondary schools in metropolitan Sydney. In the State of NSW Australia, students attend secondary school for grades 7 through 12. Math syllabi exist for each of grades 7 and 8, grades 9 and 10, and grades 11 and 12. Junior grades 7 and 8 are focused largely on consolidation of material learned through primary grades 3 through 6. In grades 9 and 10, students are streamed into Advanced, Intermediate, and Standard math levels, based on their demonstrated ability to that point. Students in senior grades 11 and 12 select both their academic subjects and level of difficulty.

Procedures. Questionnaires assessed students' math-related selfperceptions, a composite of their perceived talent and success expectancies (see Watt 2002b, 2004) and intrinsic values, in grade 10 and academic choices at grade 11. Items were those modified by Watt (2004) based on those developed by Eccles and colleagues for success expectancies and intrinsic value (see Wigfield and Eccles, 2000), but perceptions of talent were assessed in place of their ability perceptions factor. Full details of modifications and good construct validity and reliability based on the sample are reported by Watt (2002b, 2004), and sample items are presented in Appendix A.

Academic choices consisted of actual senior high school course levels at grade 11, when students were asked to indicate on the survey which course level they were studying, out of "Maths in Practice," "Maths in Society," 2U, $3 \mathrm{U}$, and the most advanced $4 \mathrm{U}$ math. Standardized progressive achievement 
tests (Australian Council for Educational Research, 1984) were used to assess students' math performance at each of grades 9 and 11 , out of a possible total score of twenty-eight. Surveys and tests were administered by the researcher in the regular classroom to maximize ecological validity. Data were collected each February near the start of the Australian academic year, and the study described here formed part of the researcher's larger study that investigates a broader range of perceptions related to math as well as English.

Analyses. To investigate the extent of gender difference in students' grade 11 math participation choices, dominance analysis (Cliff, 1993) was used (see Watt, 2002a, 2002b, for further details). Proportions of each gender selecting course that involved varying degrees of mathematics were of interest, and $d$ provides a direct measure of the extent to which one sample distribution lies above another. Gender differences were compared using multivariate analysis of variance (MANOVA) for grade 10 self-perceptions and intrinsic value and grades 9 and 11 achievement. The MANOVA analysis established whether boys and girls differed to a statistically significant degree on their average levels of math-related self-perceptions, intrinsic values, and achievement.

To measure the influences of self-perceptions, intrinsic value, and prior achievement for each of boys' and girls' choices of HSC math course level and senior high school math achievement, structural equation models were estimated using LISREL 8.54. Prior multigroup confirmatory factor analyses for boys and girls showed invariance of measurement properties across gender groups, a necessary first step before comparing structural paths for boys and girls. In these analyses, multiple imputation was used to impute missing data (Schafer, 1997). The models measured the strength of these relationships separately for boys and girls. Grade 9 math achievement was included as a control, followed by grade 10 self-perceptions and intrinsic value, with grade 11 HSC course level and grade 11 achievement as the outcomes. Estimated structural paths were from grade 9 achievement to grade 10 perceptions and grade 11 outcomes, from grade 10 perceptions to grade 11 outcomes, and from grade 11 course level to grade 11 achievement. These relationships that were modeled are represented schematically in Figure 3.1. Construct correlations and measurement paths were freely estimated, although the error variance for grade 11 course level was necessarily fixed to zero. The error covariance between grade 10 self-perceptions and grade 10 intrinsic value was freely estimated, due to the extent of correlation between these constructs measured at the same time point. Correlations between each pair of latent constructs are presented in Appendix B for boys and girls.

\section{Results}

Results are reported in two main sections. The first part presents the findings regarding gender group differences in adolescents' mathematical participation, achievement, and perceptions. Second, relationships among 


\section{Figure 3.1. Modeled Relationships Among Participation, Achievement, and Perceptions}

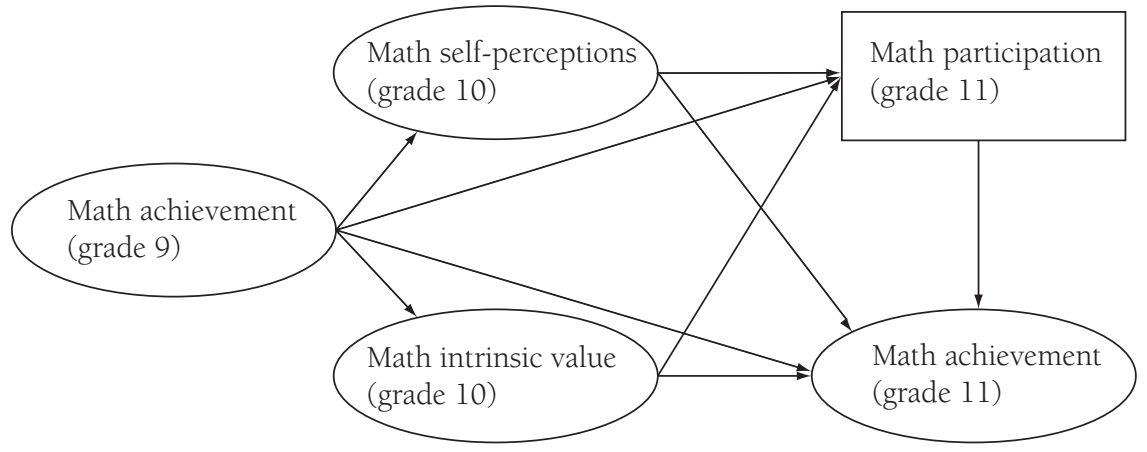

participation, achievement, and perceptions are described, separately for males and females.

Gender Differences in Participation, Achievement, and Perceptions. First, proportions of boys and girls selecting increasingly difficult senior high school math courses were compared. As shown in Figure 3.2, a larger proportion of girls undertook lower math HSC levels, a pattern that was reversed for the higher levels of HSC math. The d statistic of .18 was statistically significant at $p<.05$. The distribution for boys' math HSC levels therefore lay 18 percent above the distribution for girls, a substantial effect of boys choosing to participate in higher levels of HSC math.

Second, possible gender differences in math achievement were compared. There were no statistically significant gender differences at grade $9(F(1,401)$ $=.75 p=.39)$ or grade $11(F(1,346)=.04 p=.84)$, meaning that boys and girls had similar mathematical performance at both grades. Finally, gender differences in students' perceptions were compared. Boys rated their selfperceptions $(F(1,379)=30.70 p<.001$; boys: $M=5.03, S D=.88$; girls: $M=$ $4.52, S D=.87)$ and intrinsic value $(F(1,353)=9.35 p=.002$; boys: $M=3.95$, $S D=1.71$; girls: $M=3.43, S D=1.39$ ) significantly higher than girls did on the seven-point scales. On average, then, boys had higher math self-perceptions and intrinsic value than girls. This finding may seem counterintuitive given that boys had equivalent levels of mathematical achievement to girls.

Gendered Relationships Among Participation, Achievement, and Perceptions. Boys are participating in more difficult math courses than females in senior high school. What explains these differences? To answer this question, I tested the relations among math participation, achievement, and perceptions. Structural equation models for each of boys and girls exhibited good fit across a range of frequently emphasized fit indexes, (boys: normal theory weighted least-squared $\chi^{2}=227.365$ d.f. $=81$, RMSEA $=$ $0.083, \mathrm{NFI}=.942, \mathrm{NNFI}=.947, \mathrm{GFI}=.896, \mathrm{AGFI}=.846$; girls: normal 


\section{Figure 3.2. Proportions of Boys and Girls Electing Increasingly Difficult Math Courses in NSW High School}

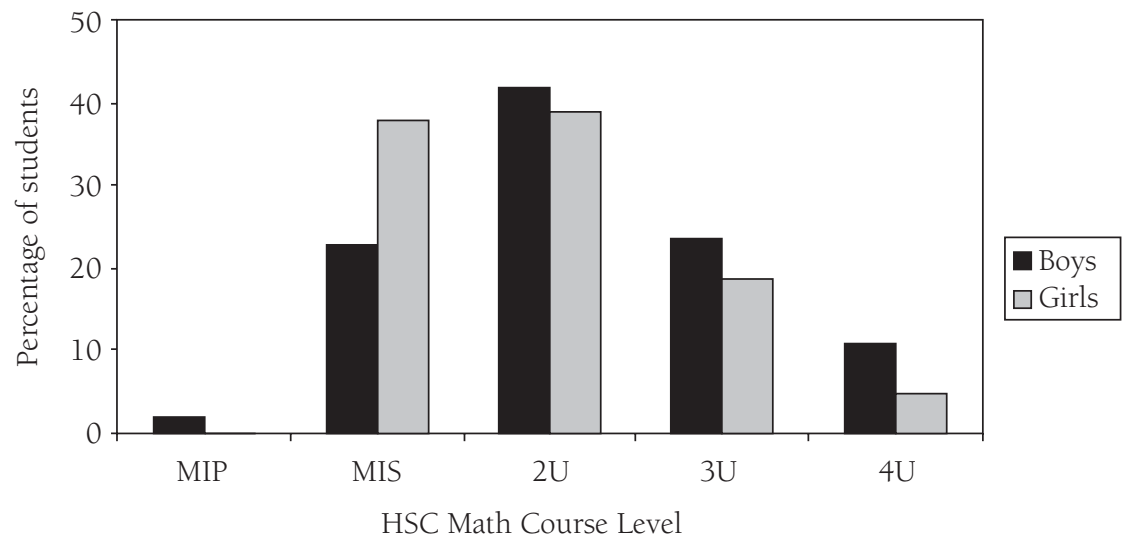

Note: High school math courses are depicted from lowest to highest. MIP = "Maths in Practice." MIS = "Maths in Society." $2 U=2$-unit maths. $3 U=3$-unit maths. $4 U=4$-unit maths.

theory weighted least-squared $\chi^{2}=223.346$ d.f. $=81$, RMSEA $=0.095$, NFI $=.933, \mathrm{NNFI}=.943, \mathrm{GFI}=.868, \mathrm{AGFI}=.804)$, and there were no large modification indexes. The data therefore fit the models well, a necessary requirement before interpreting the relationships measured in these models. For reasons of parsimony, only statistically significant $(p<.05)$ completely standardized structural paths will be summarized.

Relationships among math participation, achievement, and perceptions are graphically depicted in Figure 3.3. Paths with higher values, up to a value of 1 , denote the strongest relationships. For the goals of this study, the paths of greatest interest were the ones with an impact on math participation: from intrinsic value, self-perceptions, and achievement. As can be seen from Figure 3.3, these all had an impact on choices for senior high school math participation. Math intrinsic value and grade 9 mathematical achievement were the strongest influences on grade 11 HSC math choices, followed by self-perceptions (of perceived mathematical talent and expectations for success). For boys, intrinsic value had the strongest influence, followed by prior math achievement and then self-perceptions. For girls, intrinsic value and prior achievement had more similar strength of influence on grade 11 math course choices, again followed by self-perceptions. Self-perceptions appeared to have an impact on grade 11 course choices more strongly for girls than for boys.

Grade 9 math achievement directly influenced grade 10 self-perceptions, grade 10 intrinsic value, and grade 11 math achievement. That is, adolescents who had high math achievement in grade 9 were likely to have high selfperceptions and intrinsic value in grade 10 and high achievement in grade 


\section{Figure 3.3. Relationships Among Participation, Achievement, and Perceptions for Boys and Girls}

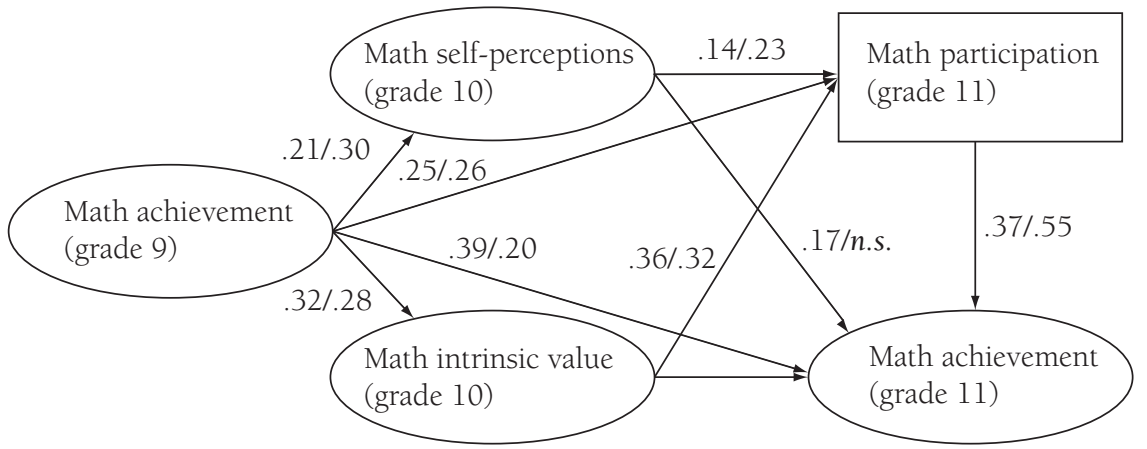

Note: Each pair of parameter estimates lists completely standardized estimates for boys and girls from separate structural equation models.

11 (and conversely for those with low grade 9 math achievement). There appeared to be a stronger link between girls' grade 9 achievement and their grade 10 self-perceptions than was the case for boys, while boys' grade 9 achievement appeared to relate more with their grade 11 achievement than was the case for girls. Grade 10 self-perceptions had additional direct effects on boys' grade 11 achievement. Despite no significant structural path from grade 10 self-perceptions to grade 11 math achievement for girls (beta $=.03$, n.s.), the correlation between these two constructs for girls (.39) was similar to that for boys (.38), indicating a possible suppression effect, likely due to the stronger correlation between self-perceptions and intrinsic value for girls (.54) than for boys (.34). Although grade 10 intrinsic value did not directly influence subsequent math achievement, it did have an indirect influence mediated by its effect on grade 11 HSC math course.

In sum, higher math-related intrinsic value, prior achievement, and self-perceptions led to participation in higher levels of HSC math. Higher levels of prior mathematical achievement, as well as high math-related selfperceptions, led to higher subsequent mathematical achievement.

\section{Discussion}

The NSW Australian system provides a good test of the extent of gender differences in math enrollments in senior high school. In the NSW context, gender differences in math enrollments also emerge, and fewer girls undertake the more difficult math courses. Gendered math enrollment is clearly a problem of international concern. These differences are not due to differences in boys' and girls' math achievement but are explained by adolescents' perceptions related to math. 
We may well be concerned that girls continue to prematurely restrict their educational and career options even today through lower levels of participation in math-the critical filter that channels access to many careers high in status and salary. In this study, robust gender differences in math participation were identified, even among this sample of adolescents from the upper-middle-class socioeconomic spectrum. In fact, gender differences were apparent at the very first point where adolescents were able to choose the level of mathematics that they wished to undertake. The NSW Australian senior high school course selection structure provides adolescents with the opportunity to choose the extent of their involvement in higher-order and more complex math. In this context, girls began to opt out of the math pipeline at their first opportunity in senior high school.

Significantly, this lower participation of girls in more difficult senior high school math was not due to higher male achievement, either prior to or concurrent with the time at which students chose their grade 11 math courses. These findings parallel evidence from the undergraduate university context that equally prepared women defect from math at a higher rate than men, especially in their early years of study (Oakes, 1990). Clearly, explanations other than gender differences in mathematical achievement must explain gendered math participation.

The strongest influence on math participation for both boys and girls was the extent to which they were interested in and liked math. A secondary factor was adolescents' self-perceptions about their own math talent and their expectations for mathematical success. For girls, this effect appeared almost as strong as the influence of their prior mathematical achievement, while for boys it had a somewhat weaker impact. Self-perceptions also had a modest influence on senior high school math achievement, even when controlling for prior achievement in math.

Because intrinsic value and self-perceptions affect math participation over and above the influence of prior mathematical achievement, we need to ask about the sources of adolescents' mathematical perceptions. Are boys and girls equally interested in math? Boys indicated that they liked math more than girls did, similar to findings of previous research (Benbow and Stanley, 1984; Fredricks and Eccles, 2002; Updegraff, Eccles, Barber, and O'Brien, 1996) and consistent with Eccles and colleagues' argument that girls do not choose math because they do not value it as much as boys do.

Do boys and girls have similar self-perceptions related to math in line with their similar levels of math achievement? Do they believe that they are equally able at math, and are their perceptions based on their actual mathematical achievement? Despite equivalent levels of mathematical achievement, boys rated their math talent and success expectancies significantly higher than girls did. These findings are consistent with previous research (Eccles and others, 1989; Eccles, Wigfield, Harold, and Blumenfeld, 1993; Singer and Stake, 1986). Might this mean that there is less of an objective reality basis for boys' self-perceptions? If so, we would expect that boys' 
self-perceptions would be less strongly related to their actual achievement than girls'. This was indeed the case, providing support for the notion that boys' self-perceptions are less realistic than girls', as Crandall (1969) suggested more than thirty years ago. In contrast, the stronger association between girls' self-perceptions and their prior mathematical achievement supports the idea that girls' self-perceptions are more realistic.

Greater realism on the part of girls appears to translate into levels of math participation more commensurate with their abilities than is the case for boys. Further support for this interpretation comes from girls' later math achievement in senior high school also relating more strongly to their HSC course selections. Perhaps it is boys who are overrepresented in math rather than girls who are underparticipating. Boys may be participating in math to a higher degree than their actual ability levels warrant. This could create a spiral of benefits for boys, whose participation choices lead to preparation in more advanced math, which then scaffolds their access to certain types of careers and educational opportunities. Even moderate levels of achievement in high-level math may promote this access for boys. Given the current critical shortage of people entering math-related careers (Herzig, 2004; Stage and Maple, 1996), it would be somewhat silly to suggest that parents and educators should discourage boys' participation in high-level math. Rather, we should be focused on actively promoting girls' greater participation, through targeting their lower intrinsic values and self-perceptions.

\section{Implications and Recommendations}

Because intrinsic value and self-perceptions were important influences on the extent of boys' and girls' later math participation, girls' lower intrinsic value and self-perceptions are of particular concern. Such differences are evident even in very young boys and girls. A qualitative study based on seven women who had opted out of math following completion of an undergraduate math major (Stage and Maple, 1996) identified that interest in math and beliefs about mathematical aptitude since early childhood had been the main determinants of their decision to complete a math major. A study by Jacobs and her colleagues (Jacobs and others, 2002) identified higher math values and ability perceptions for boys from as early as the second grade. An earlier study based on the sample used in this chapter also established that boys maintained higher levels of intrinsic value and selfperceptions related to math throughout secondary school (Watt, 2004). Collectively these findings show that gender differences in math-related intrinsic value and self-perceptions are in place from early on and imply that they need to be addressed from childhood. We need research studies to focus on exactly when it is that young boys' and girls' math intrinsic values and self-perceptions begin to diverge, so that intervention efforts can be concentrated from that point.

As argued by Eccles and her colleagues in the expectancy-value literature (Eccles (Parsons) and others, 1983; Eccles (Parsons), 1984a; Eccles, 
1984b), values were indeed most predictive of senior high school math choices in the context of NSW Australia. Intrinsic value was the strongest predictor for both boys and girls, suggesting that efforts to heighten adolescents' interest in and liking for math should promote boys' and girls' participation in the math pipeline. Since math self-perceptions had a weaker impact on math participation (especially for boys), intervention efforts focused on promoting adolescents' self-perceptions of talent and expectations for success may be less effective.

Key factors that have previously been found to influence task interest include personal relevance, familiarity, novelty, activity level, and comprehensibility (Hidi and Baird, 1986). What we need to be asking as educators is whether these factors are equally fulfilled for both boys and girls in math classrooms. Eccles and her colleagues have demonstrated that girls are engaged by activities that they perceive to be socially meaningful and important (Vida and Eccles, 2003). Math, however, is often taught in skills-based, abstract, and decontextualized ways and is therefore unlikely to capture girls' interest for this reason. Making explicit connections between math and its social uses and purposes may help to heighten girls' interest. Adolescents also often have quite inaccurate ideas of what careers involve developed mathematical skills. Detailed information about the math required for a range of careers would be likely to promote girls' interest in math when their preferred careers involve mathematics.

Because boys had higher levels of intrinsic value than girls, gendered intrinsic values are influencing girls' subsequent enrollment decisions. The crucial question is why girls find math less interesting than boys do and have less liking for it. We also need to more closely examine the bases for boys' and girls' self-perceptions of their mathematical talents and expectations for success.

This study signals two clear priorities to inform intervention efforts for encouraging girls' participation in math. First, we need to understand how it is that boys come to be more interested in and like math more than girls do, and second, why it is that girls perceive themselves as having less talent and lower expectations of success at math than boys do, even though they perform similarly. Continued investigations into the origins and sources of gender differences in math intrinsic values and self-perceptions promise to shed further light on the persistent issue of female underparticipation, or male overrepresentation, in the math pipeline.

\section{References}

Australian Bureau of Statistics. Index of Education and Occupation. Sydney: Australian Bureau of Statistics, 1991.

Australian Council for Educational Research. Progressive Achievement Tests of Mathematics. Melbourne: Australian Council for Educational Research, 1984.

Bandura, A. Self-Efficacy: The Exercise of Control. New York: Freeman, 1994.

Benbow, C. P., and Minor, L. L. "Mathematically Talented Males and Females and Achievement in the High School Sciences." American Educational Research Journal, $1986,23,425-436$. 


\section{Appendix A. Sample Items for Math Constructs}

\begin{tabular}{lccl}
\hline Construct & $\begin{array}{c}\text { Number } \\
\text { of Items }\end{array}$ & \multicolumn{1}{c}{ Sample Item } & \multicolumn{1}{c}{ Anchors } \\
\hline $\begin{array}{c}\text { Talent } \\
\text { perceptions }\end{array}$ & 7 & $\begin{array}{c}\text { Compared with other students } \\
\text { in your class, how talented do } \\
\text { you consider yourself to be at } \\
\text { maths? }\end{array}$ & $\begin{array}{c}1 \text { (Not at All) to 7 (Very } \\
\text { Talented) }\end{array}$ \\
$\begin{array}{c}\text { Success } \\
\text { expectancies }\end{array}$ & 3 & $\begin{array}{c}\text { How well do you expect to do } \\
\text { in your next maths test? } \\
\text { Intrinsic value } \\
\text { How much do you like maths, } \\
\text { compared with your other } \\
\text { subjects at school? }\end{array}$ & $\begin{array}{l}\text { 1 (Not at All) to } 7 \text { (Very } \\
\text { (Much Less) to 7 } \\
\text { (Much More) }\end{array}$ \\
\hline
\end{tabular}

Appendix B. Correlations Among Latent Math Constructs

\begin{tabular}{lccccc}
\hline & $1 . \mathrm{M} / \mathrm{F}$ & 2. M/F & 3. M/F & 4. M/F & $5 . \mathrm{M} / \mathrm{F}$ \\
\hline 1. Grade 11 math achievement & - & & & & \\
2. HSC math level & $.60 / .68$ & - & & & \\
3. Grade 10 self-perceptions & $.38 / .39$ & $.32 / .48$ & - & & \\
4. Grade 10 intrinsic value & $.41 / .42$ & $.49 / .52$ & $.34 / .54$ & - & \\
5. Grade 9 math achievement & $.59 / .45$ & $.40 / .42$ & $.21 / .30$ & $.32 / .28$ & - \\
\hline
\end{tabular}

Note. 'M' refers to males and 'F' to females.

Benbow, C. P., and Stanley, J. C. "Gender and the Science Major: A Study of Mathematically Precocious Youth.” In M. W. Steinkamp and M. L. Maehr (eds.), Women in Science. Greenwich, Conn.: JAI Press, 1984.

Betz, N. E., and Fitzgerald, L. F. The Career Psychology of Women. Orlando, Fla.: Academic Press, 1987.

Bornholt, L. J., Goodnow, J. J., and Cooney, G. H. "Influences of Gender Stereotypes on Adolescents' Perceptions of Their Own Achievement." American Educational Research Journal, 1994, 31, 675-692.

Cliff, N. "Dominance Statistics: Ordinal Analyses to Answer Ordinal Questions." Psychological Bulletin, 1993, 114, 494-509.

Crandall, V. C. "Sex Differences in Expectancy of Intellectual and Academic Reinforcement." In C. P. Smith (ed.), Achievement-Related Motives in Children. New York: Russell Sage Foundation, 1969.

Deci, E. L., and Ryan, R. M. Intrinsic Motivation and Self-Determination in Human Behavior. New York: Plenum, 1985.

Deci, E. L., Vallerand, R. J., Pelletier, L. C., and Ryan, R. M. "Motivation and Education: The Self-Determination Perspective." Educational Psychologist, 1991, 26, 325-346.

Eccles (Parsons), J. S. "Sex Differences in Mathematics Participation. In M. W. Steinkamp and M. L. Maehr (eds.), Advances in Motivation and Achievement. Greenwich, Conn.: JAI Press 1984a.

Eccles, J. S. "Sex Differences in Achievement Patterns." In T. Sonderegger (ed.), Nebraska Symposium on Motivation. Lincoln: University of Nebraska Press, 1984b.

Eccles, J. S. "A Model of Student Enrollment Decisions." Educational Studies in Mathematics, 1985, 16, 311-314. 
Eccles, J. S. "Subjective Task Value and the Eccles et al. Model of Achievement-Related Choices." In A. J. Elliot and C. S. Dweck (eds.), Handbook of Competence and Motivation. New York: Guilford Press, 2005.

Eccles, J. S., Adler, T. F., and Meece, J. L. "Sex Differences in Achievement: A Test of Alternate Theories." Journal of Personality and Social Psychology, 1984, 46, 26-43.

Eccles, J. S., and Wigfield, A. "In the Mind of the Actor: The Structure of Adolescents' Achievement Task Values and Expectancy-Related Beliefs." Personality and Social Psychology Bulletin, 1995, 21, 215-225.

Eccles, J. S., Wigfield, A., Harold, R., and Blumenfeld, P. B. "Age and Gender Differences in Children's Self- and Task-Perceptions During Elementary School." Child Development, 1993, 64, 830-847.

Eccles (Parsons), J. S., and others. "Expectancies, Values, and Academic Behaviors." In J. T. Spence (ed.), Achievement and Achievement Motivation. New York: Freeman, 1983.

Eccles, J. S., and others. "Self-Concepts, Domain Values, and Self-Esteem: Relations and Changes at Early Adolescence." Journal of Personality, 1989, 57, 283-310.

Fredricks, J. A., and Eccles, J. S. "Children's Competence and Value Beliefs from Childhood Through Adolescence: Growth Trajectories in Two Male-Sex-Typed Domains." Developmental Psychology, 2002, 38, 519-533.

Friedman, L. "Mathematics and the Gender Gap: A Meta-Analysis of Recent Studies on Sex Differences in Mathematical Tasks." Review of Educational Research, 1989, 59, $185-213$.

Green, D. R. The Aptitude-Achievement Distinction. New York: McGraw-Hill, 1974.

Hackett, G. "Role of Mathematics Self-Efficacy in the Choice of Math-Related Majors of College Women and Men: A Path Analysis." Journal of Counseling Psychology, 1985, $32,47-56$.

Harter, S. "A New Self-Report Scale of Intrinsic Versus Extrinsic Orientation in the Classroom: Motivational and Informational Components." Developmental Psychology, 1981, 17, 300-312.

Heller, K. A., and Parsons, J. E. "Sex Differences in Teachers' Evaluative Feedback and Students' Expectancies for Success in Mathematics." Child Development, 1981, 52, $1015-1019$.

Herzig, A. H. "Becoming Mathematicians: Women and Students of Color Choosing and Leaving Doctoral Mathematics." Review of Educational Research, 2004, 74, 171-214.

Hidi, S., and Baird, W. "Interestingness-a Neglected Variable in Discourse Processing." Cognitive Science, 1986, 10, 179-194.

Hyde, J. S., Fennema, E., and Lamon, S. J. "Gender Differences in Mathematics Performance: A Meta-Analysis." Psychological Bulletin, 1990, 107, 139-155.

Jacobs, J. E., and others. "Changes in Children's Self-Competence and Values: Gender and Domain Differences Across Grades One Through Twelve." Child Development, 2002, 73, 509-527.

Lent, R. W., Brown, S. D., and Hackett, G. "Toward a Unifying Social Cognitive Theory of Career and Academic Interest, Choice, and Performance." Journal of Vocational Behavior, 1994, 45, 79-122.

MacCann, R. "Sex Differences in Participation and Performance at the NSW Higher School Certificate After Adjustment for the Effects of Differential Selection." Australian Journal of Education, 1995, 39, 163-188.

Meece, J. L., Wigfield, A., and Eccles, J. S. "Predictors of Math Anxiety and Its Influence on Young Adolescents' Course Enrollment Intentions and Performances in Mathematics." Journal of Educational Psychology, 1990, 82, 60-70.

Oakes, J. Lost Talent: The Underparticipation of Women, Minorities, and Disabled Persons in Science. Santa Monica, Calif.: Rand, 1990.

Schafer, J. L. Analysis of Incomplete Multivariate Data. London: Chapman and Hall, 1997. Secada, W. "Agenda Setting, Enlightened Self-Interest, and Equity in Mathematics Education." Peabody Journal of Education, 1989, 66(2), 22-56. 
Sells, L. W. "Mathematics: The Invisible Filter." Engineering Education, 1980, 70, 340-341.

Simpkins, S. D., Davis-Kean, P. E., and Eccles, J. S. "Math and Science Motivation: A Longitudinal Examination of the Links Between Choices and Beliefs." Developmental Psychology, forthcoming.

Singer, J. M., and Stake, J. E. "Mathematics and Self-Esteem: Implications for Women's Career Choices." Psychology of Women Quarterly, 1986, 10, 339-352.

Stage, F. K., and Maple, S. A. "Incompatible Goals: Narratives of Graduate Women in the Mathematics Pipeline." American Educational Research Journal, 1996, 33, 23-51.

Updegraff, K. A., Eccles, J. S., Barber, B. L., and O’Brien, K. M. "Course Enrollment As Self-Regulatory Behavior: Who Takes Optional High School Math Courses?" Learning and Individual Differences, 1996, 8, 239-259.

Vida, M., and Eccles, J. S. "Predicting Mathematics-Related Career Aspirations and Choices." Paper presented at the Society for Research in Child Development Biennial Conference, Tampa, Fla., Apr. 2003.

Watt, H.M.G. "Exploring Adolescent Personal and Social Gender Stereotypes About Maths: An Explanation for Continued Gender Differences in Participation?" Change: Transformations in Education, 2002a, 5(2), 39-54.

Watt, H.M.G. "Gendered Achievement-Related Choices and Behaviours in Mathematics and English: The Nature and Influence of Self-, Task- and Value Perceptions." Unpublished doctoral dissertation, University of Sydney, 2002b.

Watt, H.M.G. "Development of Adolescents' Self Perceptions, Values and Task Perceptions According to Gender and Domain in 7th Through 11th Grade Australian Students." Child Development, 2004, 75, 1556-1574.

Watt, H.M.G. "The Role of Motivation in Gendered Educational and Occupational Trajectories Related to Maths." Educational Research and Evaluation, forthcoming.

Watt, H.M.G., and Bornholt, L. "Gendered Perceptions of Talent and Planned Participation in Mathematics." Australian Journal of Career Development, 1994, 3(3), 43-50.

Watt, H.M.G., Eccles, J. S., and Durik, A. M. "The Ontogeny of Ability Self Concepts and Subjective Task Values." Unpublished manuscript, 2005.

Wigfield, A. "Expectancy-Value Theory of Achievement Motivation: A Developmental Perspective." Educational Psychology Review, 1994, 6, 49-78.

Wigfield, A., and Eccles, J. S. "Expectancy-Value Theory of Achievement Motivation." Contemporary Educational Psychology, 2000, 25, 68-81.

HELEN M. G. WATT is from the Gender and Achievement Research Program and the School of Education at the University of Michigan. 